\title{
Anti-diabetic Potential of Some Myanmar Traditional Medicinal Plants
}

\section{Abstract}

Plant derived antioxidants and $\alpha$-glucosidase inhibitors are widely used in dietary supplements and have been investigated for the prevention to human neurodegenerative disorders, diabetes, and inflammation. Several herbs have been known to cure and control diabetes without causing any side effects. The present review is an attempt on reveal the plants which have been experimentally studied for anti-diabetic activity in the last ten years.

Keywords: Medicinal plant; Sntioxidant activity; $\alpha$-glucosidase inhibitors; Sntidiabetic activity; Myanmar

Mini Review
Volume 8 Issue 2 - 2017
Phyu Phyu Myint*
Department of Chemistry, Sittway University, Myanmar
*Corresponding author: Department of Chemistry, Sittway
University, Sittway 012001, Myanmar, Tel: +95-9-5180605;
Email: phyuphyumyint2007@gmail.com
Received: June 24, 2017 | Published: July 25, 2017

\section{Introduction}

The traditional medicine plays an important role in health care of the people especially in rural areas. Plants have always been exemplary sources of drug and many of the currently available drugs have been directly or indirectly obtained from plants [1]. Recently, the search for appropriate hypoglycemic agent has been focused on plants used in traditional medicine partly because of leads provided by traditional medicine to natural products that may be better treatments than currently used drugs. Throughout the world, many traditional plant treatments for diabetes exist, however, few have received scientific or medical scrutiny and the world Health Organization (WHO) has recommended that traditional plant treatments for diabetes warrant further evaluation [2].

At present the government of Myanmar has urged to upgrade further and extensive research on traditional methods on potent traditional drugs which can be used against certain disease that cannot be cured by western medicine and to conduct biomedical research in order to make it safer and more reliable to people. In Myanmar, diabetes mellitus is one of the major priority disease such as malaria, tuberculosis (TB), hypertension, diarrhea and dysentery, and also one of the priority disease of National Health Programme (NHP) [3].

Myanmar has rich traditional medicinal plants for the treatment of diabetes mellitus. Some of the researchers reported that a large number of herbs drug which are reputed for the treatment of diabetes mellitus [4,5]. Although these were popular plants for treatment of diabetes mellitus, scientific literature of full and systematic exploration of these natural resources with regard to hypoglycemic effect was very limited. So, some researchers in Myanmar has studied the chemical constituents and pharmacological activities of Myanmar indigenous medicinal plants and Myanmar traditional medicinal formulation (TMF) since 1994. Antidiabetes and antioxidant activities have been investigated on Tinospora cordifolia Mers. (Sindomanwe), Wedeli calendulaceae Less. (Negyagalae), Kaempferia pulchra Ridl. (Shan- pan-oot), Putranjiva roxburghi Wall. (Badi-byu), Heliotropium indicum Linn. (Sinhna-maung-gyi), Rauvolfia serpentina Linn. (Bon-ma-ya-za) root, Alstonia scholaris (L.) R. Rr. (Taung-mayo) leaf, Terminalia chebula Retz. (Phan-khar) bark, Hydrocotyl rotundifolia Roxb (Say Myhin Khwar), Orthosiphon aristafus Miq (Thagya Mageik), Eichhornia crassipes Solms. (Bay-dar), Mimusops elengi Roxb. (Kha-ye) bark, Swieteniz macrophylla King. (Mahogany) seed, Cataeva religiosa Forest (Kadet) bark, Syzygium grande (Wi) Walp. (Thabye-gyi) bark, Commelina communis Linn. (Myint-Kyut), Spirulina, Gomphrena globosa L. (Ma-nhyo-lon) and Morus alba Linn. (Po-sa). Inhibitory effect on $\alpha$ - glucosidase activity have been studied on in the fruit of Momordica charantia Linn. (Kyet-Hinn-khar), Gynura procumbers (lour.) Merr. (PyarHme, Pyar-Hme-chun), Cataeva religiosa Forest (Kadet) bark and Syzygium grande (Wi) Walp. (Thabye-gyi) bark, Commelina communis Linn. (Myint-Kyut), Spirulina, Eupatorium odoratum L. (Bizat), A.xanthioides Wall. (Chinbaung Hpala), and Lagerstroemia speciosa L. (Pyin-ma) [6-11].

\section{Methodology}

The study aimed to recollect and record, the information on anti-diabetic plants from the published literature [6-11]. All the plants recorded were used for the treatment of diabetes to reduce hyperglycemic condition, antioxidant activity and $\alpha$-glucosidase inhibition effect.

\section{Conclusion}

The traditional medicinal plants, commonly used by local practitioners for various types of ailments, were found to have high potency in hypoglycemic activity as well as in free radical scavenging and $\alpha$-glucosidase inhibition activity. From the review, it is concluded that, the medicinal plants, which possess antidiabetic activity is more abundant in nature. The review will enhance the existing knowledge of medicinal plants, and also will go a long way to helping the poor folks in locality who tend to prefer herbal therapy to conventional medicine to manage diabetes mellitus at lower cost. 


\section{Conflict of Interest}

The author declares that there is no conflict of interest that could be perceived as prejudicing the impartiality of this review.

\section{References}

1. Newman DJ, Cragg GM, Snader KM (2000) The Influence of Natural Products Upon Drug Discovery. Nat Pro Rep 17: 215-234.

2. Kavishankar GB, Lakshmidevi N, Murthy SM, Prakash HS, Niranjana SR (2011) Diabetes and Medicinal Plants. A Review, Int J Pharm Biomed Sci 2(3): 65-80.

3. May Aye Than (2002) Medicinal Plants of Myanmar, Department of Traditional Medicine, Ministry of Health, 5(2): 23-34.

4. Mya Bwin and Sein Gwan (1967) Burmese Indigenous Medicinal Plants with reputed hypoglycemic action, Myanmar Medical Research Institute, Yangon, Myanmar, p. 3-46.

5. Ashin Nagathein (1973) Pon Pya Say Abidan (Myanmar version), Kyaw Win Swe Printing Press. Yangon, Myanmar 4: 153-156.

6. Mon Mon Thu (2003) Study on the Antidiabetic Activity and Chemical Constituents of Tinospora cordifolia Mers, (Sindonmanure) and Wedelia calendulaceae Less. (Negyargalae), PhD (Dissertation), Chemistry Department, Yangon University, Yangon, Myanmar, p. 21 56.
7. Nwet Nwet Win (2005) Three Novel Pimarane Diterpenes from Rhizomes of Shan-pan-oot (Kaempferia pulchra Ridl., JMAAS 3(1): 213-224.

8. Khin Thida Wai (2006) Study on hypoglycemic effect of two selected medicinal plants; Putranjiva roxburghii Wall. (Badi-byu) and Heliotropium indicum Linn. (Sin-hna-maung-gyi) levels used in the treatment of Diabetes Mellitus. JMAAS 4(1): 243-257.

9. Hla Ngwe, Sandar Kyin and Hla Hla Nyo (2011) Chemical Analysis and $\alpha$-Glucosidase Inhibitory Effect of Bizat Leaves (Eupatorium odoratum Linn.), Universities Research Journal 4(3): 1-12.

10. Kyaw Thu (2012) Investigation of Some Organic Constituents and Evaluation of Some Biological Activities of Amomum xanthioides Wall. (Chinbaung Hpalar), PhD Dissertation, Department of Chemistry, University of Yangon, Yangon, Myanmar, p. 17-44.

11. May Thu Soe (2015) Studies on Chemical Constituents and Some Bioactivities of Lagerstroemia speciosa L. (Pyin-ma) Leaf, MRes Thesis, Department of Chemistry, Hinthada University, Hinthada, Myanmar, p. 23-34. 